DOI 10.37882/2223-2982.2020.12.08

\title{
ОРГАНИЗАЦИЯ И СОДЕРЖАНИЕ РАБОТЫ ДЕТСКОГО ИНКЛЮЗИВНОГО ТАНЦЕВАЛЬНОГО ПРОЕКТА «ПРЕОДОЛЕЙ-КА»
}

\section{ORGANIZATION AND CONTENT OF THE WORK OF THE CHILDREN'S INCLUSIVE DANCE PROJECT "PREDOLEY-KA"}

\section{A. Gonek}

Summary: The article describes how the inclusive dance project "Preodoley-ka» for children and adolescents with disorders of the musculoskeletal system, with cerebral palsy in particular, is organized and also the methodological aspects of this work. The author defines the concept of inclusion and represents the personal experience of rehabilitating children with musculoskeletal disorders in this project. The system of rehabilitation by means of choreography, which is proposed in the article, makes it possible to consolidate children's with motor impairments personal resources, stimulates active life position in them, and helps them overcome personal deformation, i.e. the result of motor and social deprivation.

Keywords: inclusion, art therapy, dance, systemic choreography, vertical, musculoskeletal disorders, cerebral palsy, technology.

\author{
Гонек Анна Олеговна \\ аспирант, Московский городской педагогический \\ университет, г. Москва \\ angonek@yandex.ru
}

Аннотация: В статье освещаются организационно-методические аспекты работы инклюзивного танцевального проекта «Преодолей-ка» для детей и подростков с нарушением опорно-двигательного аппарата, в частности с детским церебральным параличом. Раскрывается понятие инклюзии. Представлен опыт личностной реабилитации детей с нарушениями опорно-двигательного аппарата в рамках работы проекта. Предложенная система реабилитации средствами хореографии позволяет мобилизовать личностные ресурсы детей с двигательными нарушениями, способствует развитию у них активной жизненной позиции, позволяет преодолевать личностную деформацию, возникающую вследствие двигательной и социальной депривации.

Ключевые слова: инклюзия, арт-терапия, танец, системная хореография, вертикаль, нарушения опорно-двигательного аппарата, детский церебральный паралич, методика работы. $\ll \Pi$ реодолей-ка» - это детский инклюзивный танцевальный коллектив, построенный по принципу инклюзивности. В нем участвуют как дети с нарушениями опорно-двигательного аппарата, так и дети с нормальным двигательным развитием.

Инклюзивный проект «Преодолей-ка» был создан в 2010 году для социальной реабилитации детей и подростков с ограниченными возможностями здоровья - нарушениями опорно-двигательного аппарата. Рождению проекта во многом способствовал долголетний опыт работы Благотворительного Центра Активной Реабилитации Инвалидов «Преодоление» со взрослыми инвалидами с нарушениями опорно-двигательного аппарата, использующими для передвижения кресла-коляски активного типа.

Танец был выбран для работы проекта как дисциплина, которая имеет развитую и многоплановую методику, отшлифованную столетиями и постоянно совершенствующуюся. Танец задействует все тело единовременно в каждом движении. При этом танец - это всегда эмоционально окрашенное движение. Эмоции и чувства, которые человек переживает и переосмысливает, занимаясь танцем, дают сильную увлеченность и мотивацию к саморазвитию. Также танец - это социально активное поведение, коллективное творчество, способствующее воспитанию ответственности и усилению активной жизненной позиции. Цели, которые ставятся перед ребенком с нарушением опорно-двигательного аппарата схожи с задачами обычного танцора. Верное понимание и исполнение своей роли в хореографической постановке в дальнейшем поможет ребенку с инвалидностью правильно понять и исполнить свое предназначение в жизни общества.

В работах И.Ю. Левченко, О.Г. Приходько (2001) И.Г. Синельниковой, А.Я. Абкович указывается на значительный полиморфизм нарушений у детей с поражением опорно-двигательного аппарата, в частности у детей с детским церебральным параличом. Основные виды интеллектуальных нарушений при детском церебральном параличе - это задержка психического развития (до 50\%) и умственная отсталость (25\%) что свидетельствует о сочетании психического дизонтогенеза дефицитарного типа с дизонтогенезом по типу задержанного развития или недоразвития. Вместе с тем не существует прямой зависимости между тяжестью двигательной патологии и степени интеллектуальной недостаточности при детском церебральном параличе. [6] 
Также важно учитывать роль семьи и те деформации во внутренних взаимоотношениях и в социальных контактах, которые происходят с появлением в семье ребенка с ограниченными возможностями здоровья. Деформации проявляются на психологическом, социальном и соматическом уровне. [2,4,12]

Системная хореография не только развивает физически и творчески любого человека с сохранным здоровьем, но также дает ему способы решения эмоциональных проблем, является базой накопленных логических и образных знаний, поднимает его интеллектуальный уровень обогащая двигательным интеллектом, но и также способна сыграть огромную роль в реабилитации патологических двигательных и психологических процессов у ребенка с инвалидностью.

Известная американская танцовщица-новатор, основоположница свободного танца А. Дункан считала, что движения человеческого тела могут быть красивы на всякой ступени его развития, лишь бы они сохраняли гармонию с определенной ступенью зрелости. [5]

Инклюзивный танцевальный коллектив неоднороден - это его главная особенность. Приходит много уникальных детей, каждый из которых ищет самовыражения, понимания своих особенностей - как физических, так и связанным с ними психологических. По этой причине работа требует особого режима. Детям с физическими особенностями в равной степени нужна как индивидуальная работа, так и групповая. Детям без нарушений для полноценного развития больше подходит групповая работа, но с расширенными задачами. Хороший инклюзивный коллектив должен удовлетворить интересы всех своих участников.

Соответственно, детям с нарушениями опорно-двигательного аппарата рекомендовано заниматься одиндва раза в неделю на индивидуальных занятиях и однодва групповых и мелкогрупповых инклюзивных занятия.

Для здоровых участников рекомендовано два групповых занятия полнообъемной системной хореографией, два занятия спортивными гимнастическими дисциплинами и одно инклюзивное занятие в общей группе.

В работе учитывается возраст детей и по возможности, группы разделяются на младший, средний и старший состав.

Индивидуальная работа большей частью направлена на реабилитацию и развитие через системную хореографию и освоение новых двигательных возможностей, а также на подготовку ребенка с инвалидностью к участию в групповой инклюзивной работе.
Литературный критик и искусствовед, балетовед Волынский А.Л. в своей «Книге ликований» обращенной к искусству балета глубоко раскрывает значение вертикали. «В балете артистки танцуют обычно на кончиках пальцев, и на первый взгляд может показаться, что такое положение тела является чем-то противоестественным и неразумным. Чтобы выяснить этот столь существенный для балета вопрос необходимо рассмотреть природу и значение вертикальности в человеческом быту. В процессе развития, по истечении многих тысячелетий, человек спустился с дерева, стал прямо на ноги и освободил свои руки для сознательной борьбы с окружающей средой. Это момент величайшей бескровной революции, произошедшей в истории человеческого рода. Человек перестал быть горизонтальным и сделался вертикальным. С вертикальностью начинается история человеческой культуры и медленное завоевание неба и земли». [1]

На начальном этапе работы с ребенком с нарушением опорно-двигательного аппарата нужно в первую очередь, сориентировать его по вертикали, опираясь на основной закон всемирного тяготения. Для этого могут потребоваться специально настроенные технические средства реабилитации.

В индивидуальной работе используются адаптированные методики следующих видов системной хореографии: джазовая хореография, бальный танец (принципы исполнения шагов в европейской и латиноамериканской программе), классический экзерсис у станка (понятие опорной и рабочей ноги, вертикаль, выворотность и т.д.). Также в индивидуальной работе используются уникальные комплексы упражнений, которые сформировались и показывают положительные результаты в работе коллектива на протяжении нескольких лет. [3]

\section{Упражнения, учитываюшие реабилиташию}

Комплекс №1. Для неходящих детей с детским церебральным параличом.

Комплекс №2. Для ходящих детей с детским церебральным параличом.

Комплекс №3. Для детей, пользующихся активной коляской. Группа упражнений на работу рук.

Комплекс №4. Упражнения у станка. Группа упражнений на укрепление корпусных мышц для поддержания равновесия корпуса.

Комплекс №5. Группа танцевальных фигур и движений на коляске.

Комплекс №6. Группа движений на взаимодействие в 
паре (ведение и следование).

Комплекс №7. Для детей, пользующихся подлокотными тростями.

Также ведется отдельная работа с участниками проекта, использующими протезы нижних конечностей.

\section{Групповые упражнения}

Упражнения для совместных инклюзивных занятий: универсальная хореографическая лексика.

Инклюзивный комплекс №1. Упражнения на индивидуальных ковриках.

Инклюзивный комплекс №2. Упражнения с обручем.

Инклюзивный комплекс №3. Упражнения со скакалкой.

Инклюзивный комплекс №4. Упражнения сидя на стуле.

Инклюзивный комплекс №5. Упражнения на ковровой дорожке.

Обязательной частью групповой работы являются инклюзивные игры.

\section{Хореография как инструмент познания мира}

Каждому возрасту присущи свои психологические особенности. Их необходимо учитывать при привлечении ребенка к какому-либо действию. Нельзя просто заставить ребенка учить практическую или научную дисциплину, а ребенка с инвалидностью выполнять задания по собственной реабилитации. Ребенка важно заинтересовать. Эту задачу успешно решает занятие творчеством. Творческие задачи должны соответствовать уровню развития ребенка. Поэтому в проекте тема хореографии для младших детей берется более широко. Она может включать в себя такие разделы, как просто статические позы, различные движения начального уровня развития, ритмические маховые движения даже без музыки, развивающие игры, общение на различные темы в широком диапазоне. Игры на развитие внимания, партнерства и чувство группы. [3]

\section{Психология инкАюзивного комлектива}

Психология - одно из обязательных направлений в работе инклюзивного коллектива. Ее ведет специальный психолог, который присутствует на всех занятиях. В обязанности психолога входит отбор участников проекта. Консультирование родителей. Создание благоприятных психологических условий для работы педагогов-хоре- ографов. Психолог участвует во всех занятиях проекта, следит за эмоциональным состоянием участников с инвалидностью при индивидуальной работе, помогает солистам психологически справиться со своей ролью в хореографических номерах. Психолог в проекте «Преодолей-ка» входит в художественный состав коллектива. [7,10]

На групповых занятиях психолог следить за правильным психологическим климатом в коллективе. Поддерживает участников, только пришедших в коллектив, отслеживает участников, выпадающих из общей работы, выявляет причины. Проводит индивидуальные и групповые консультации для родителей.

Также психолог ведет работу с педагогами проекта и командообразующую работу.

На основании работы психолога был создан внутрений «Кодекс инклюзивного коллектива». Он закрепляет отработанные нормы поведения и заключает в себе правила, помогающие сохранению коллектива.

Реабилитация детей с двигательными нарушениями осуществлялась в рамках детского инклюзивного танцевального проекта «Преодолей-ка» в период с 2010 по 2020 г.г. в г. Москве, и г. Санкт-Петербурге.

Всего в проекте участвуют 10 детей с нарушения опорно-двигательного аппарата, это дети с детским церебральным параличом (спастическая диплегия, атонически-астатсческая и гиперкинетическая формы), спина бифида (атрофия нижних конечностей), дети с орфанными заболеваниями, проявляющимися в виде различных дефектов костной, хрящевой и соединительной ткани и 16 детей без отклонений в развитии разного возраста.

Для выявления актуального уровня личностного развития детей с детским церебральным параличом и его динамических показателей на всех этапах исследования нами использовался диагностический комплекс, основанный на методических разработках таких авторов, как Т.И. Кузьмина, 2015, И.Ю. Левченко, 2008-2014, К.А. Э.И. Танюхина, Семенова, В.П. Шестаков, С.А. Стеценко. Е.М. Старобина, Т.А. Нилова, А.А. Дыскин, Э.Н. Демина, 1998, Т.Н. Симонова, 2002, И.И. Мамайчук, 2001, и др.

Для динамического изучения уровня толерантности и особенностей отношения нормально развивающихся детей к сверстникам с двигательными нарушениями нами использовалась анкета «Уровень сформированности толерантности у школьников».

По мере реализации каждого этапа данного проекта на первый план выступали задачи, связанные не только с расширением двигательных возможностей 
Степень функциональной зависимости от окружающих детей с ДЦП

до и после реализации экспериментальной программы

\begin{tabular}{|c|c|c|c|c|c|c|c|c|}
\hline \multirow[b]{3}{*}{ Высокая } & \multicolumn{4}{|c|}{ Дети с нарушениями опорно-двигательного аппарата } & \multicolumn{4}{|c|}{ Нормально развивающиеся дети } \\
\hline & \multicolumn{2}{|c|}{ До эксперимента } & \multicolumn{2}{|c|}{ После эксперимента } & \multicolumn{2}{|c|}{ До эксперимента } & \multicolumn{2}{|c|}{ После эксперимента } \\
\hline & 8 & $76,7 \%$ & 2 & $23,23 \%$ & 2 & $12,33 \%$ & - & - \\
\hline средняя & 2 & $23,23 \%$ & 5 & $43,43 \%$ & 10 & $67,61 \%$ & 6 & $41,00 \%$ \\
\hline \multirow[t]{3}{*}{ низкая } & - & - & 3 & $33,33 \%$ & 4 & $20,05 \%$ & 10 & $59,00 \%$ \\
\hline & 10 & $100 \%$ & 10 & $100 \%$ & 16 & $100 \%$ & 16 & $100 \%$ \\
\hline & \multicolumn{4}{|c|}{10} & \multicolumn{4}{|c|}{16} \\
\hline
\end{tabular}

детей с двигательными нарушениями, но и формирование партнерского взаимодействия со сверстниками при создании танцевальных номеров, совместного обмена достижениями, культуры ведения диалога в ситуациях различной интенсивности и содержательной направленности социального взаимодействия [8,9,11,].

В рамках проекта сформировалась особенная реабилитационная среда на основе успешно функционирующей социальной модели инклюзивной коммуникации, что позволяет осуществлять коррекцию социальных навыков и оказывает положительное влияние на процесс социализации детей с нарушениями опорно-двигательного аппарата, с одной стороны, а также обеспечивает возможности формирования социальной толерантности, умения взаимодействовать со сверстниками с двигательными нарушениями, не имеющих отклонений в развития.

Помимо задач, направленных на совершенствование и стимуляцию процесса социализации детей с тяжелыми двигательными нарушениями, в процессе работы над танцевальными номерами предоставлялись широкие возможности для осуществления коррекции нарушенных двигательных, психических и коммуникативноречевых функций.

В 2020 году нами был проведен контрольный экспе- римент, направленный на оценку эффективности проведенной работы, определение характера личностных изменений детей с нарушениями опорно-двигательного аппарата и их сверстников, уровня толерантности нормально развивающихся детей, показателей социальной дезадаптации детей с двигательными нарушениями и членов их семей.

Полученные данные указывают на высокую эффективность преодоления личностных деформаций в процессе занятий танцами. Отмечается улучшение показателей детей с ДЦП в развитии коммуникативно-речевых и социальных функций (36,97 \% и 49,24 \% соответственно). За десять лет экспериментальной работы существенно снизились и показатели функциональной зависимости детей с нарушениями опорно-двигательного аппарата от окружающих, изменился характер взаимоотношений в семьях, воспитывающих детей с двигательными нарушениями.

Таким образом, описанный опыт детского инклюзивного танцевального проекта «Преодолей-ка» для преодоления личностной деформации и развития социальной адаптации детей с двигательными нарушениями в среде нормально развивающихся сверстников экспериментально доказал необходимость широкого внедрения подобных технологий в комплексную систему реабилитации детей с тяжелыми двигательными нарушениями.

\section{ЛИТЕРАТУРА}

1. Волынский А.Л. Книга ликований Азбука классического танца. Издание хореографического техникума, Ленинград, 1925.

2. Вяхякуопус Е. Социальная реабилитация инвалидов с нарушениями сенсорной, двигательной и интеллектуальной сферы. Учебно-методический комплекс [Текст] / Е. Вяхякуопус, В. 3. Кантор. - М. : Издательство «Папирус», 2009.

3. Гонек А.О. Ёлкин Е.А. Инклюзивный хореографический коллектив методика работы, г. Москва, Фонд президентских грантов, 2019.

4. Грибанова М.Б. Творческая реабилитация как путь адаптации детей-инвалидов в обществе [Текст] / М.Б. Грибанова. - М., 2004. С. 66.

5. Дункан А. Танец будущего. Моя жизнь И. Шнейдер. Встречи с Есениным. Ростов-на -Дону «Феникс» 1998.

6. Жигорева М.В. Левченко И.Ю. Дети с комплексными нарушениями развития, диагностика и сопровождение, Москва, 2016.

7. Левченко И.Ю. Детский церебральный паралич как смешанный вариант дизонтогенеза [Текст] / И.Ю. Левченко // Актуальные проблемы междисциплинарного подхода к этапной комплексной реабилитации детей с церебральным параличом: материалы научно-практического семинара с международным участием, 28-29 марта 2013 г. / ГОУ ВПО МГПУ. - М., 2013.

8. Левченко И.Ю. Артпедагогика и арттерапия в специальном образовании: учеб. для студ. сред. и высш. пед. учеб. заведений [Текст] / Е.А. Медведева, 
И.Ю. Левченко, Л.Н. Комиссарова, Т.А. Добровольская. - М.; Издательский центр «Академия», 2001 - 24с.

9. Л Левченко, И.Ю. Технологии обучения и воспитания детей с нарушениями опорно-двигательного аппарата [Текст] / Левченко И.Ю., Приходько 0.Г. - М.; Издательский центр «Академия», 2001 - 192с.

10. Приходько О.Г. Концептуальные основы системы ранней комплексной дифференцированной коррекционно-развивающей помощи детям с церебральным параличом [Текст] / Приходько 0.Г. // Специальная педагогика и специальная психология: современные проблемы теории, истории, методологии: материалы международного теоретико-методологического семинара / ГОУ ВПО МГПУ. — М., 2009.

11. Семёнова К.А. Актуальные вопросы проблемы детского церебрального паралича [Текст] / Семёнова К.А., Левченкова И.Ю. // Актуальные проблемы междисциплинарного подхода к этапной комплексной реабилитации детей с церебральным параличом: материалы научно-практического семинара с международным участием, 28-29 марта 2013 г. / ГОУ ВПо МГПУ. - М., 2013.

12. Ткачева В.В. Семья ребенка с ограниченными возможностями здоровья, Москва, 2014.

$$
\text { (с) Гонек Анна Олеговна (angonek@yandex.ru). }
$$

Журнал «Современная наука: актуальные проблемы теории и практики»

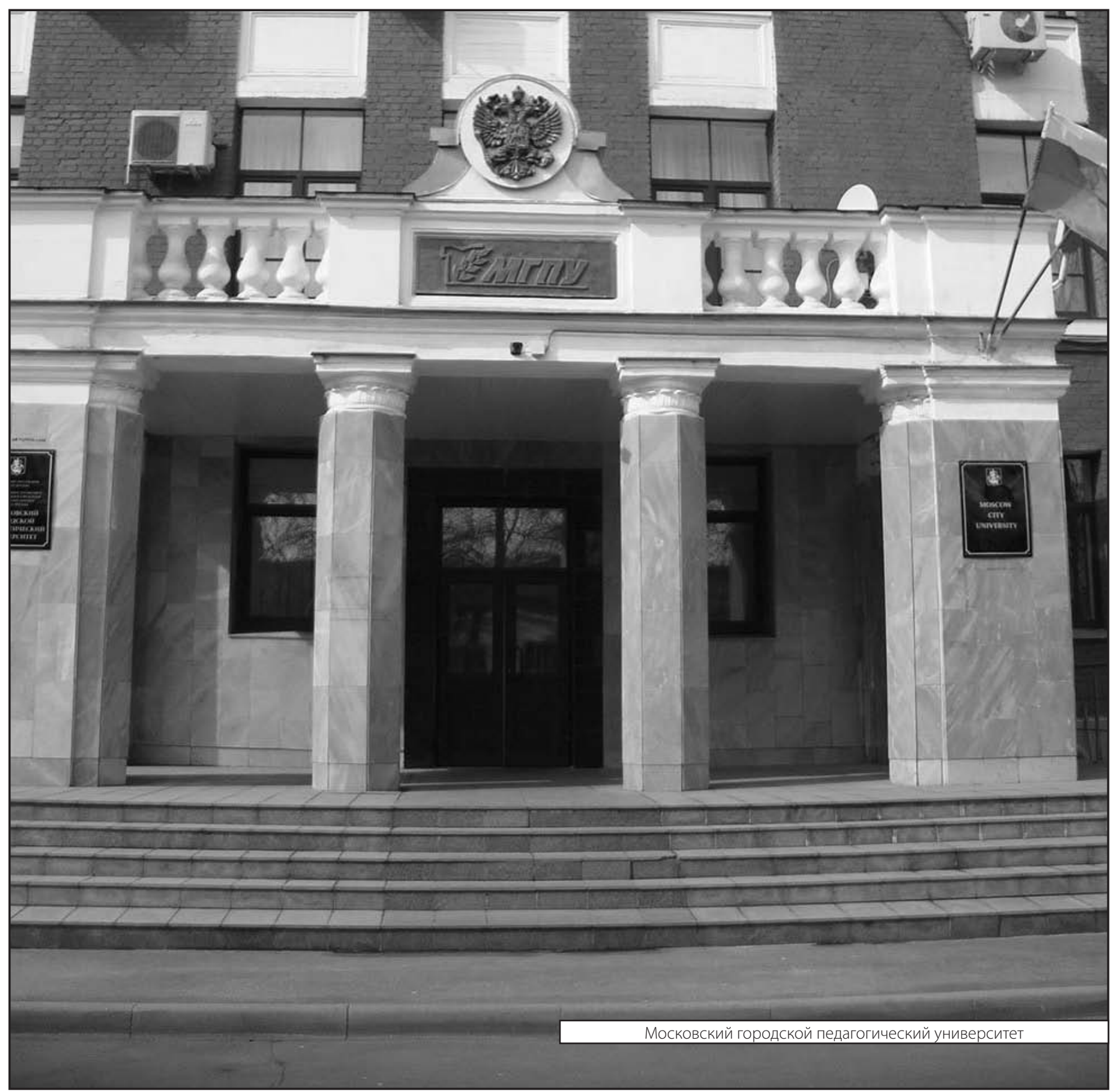

